\title{
Ice sheets and continental drift
}

\author{
Gar'Th W. PALTRIDGe \\ Antarchic Cooperalive Research Centre, Box 252C, Hobarl. Tasmania 7004, Australia
}

\begin{abstract}
Cycles of ice-sheet loading during glacial periods of the Earth's history induce horizontal velocities in the uppermost mantle which may be of the same order as those of continental drift. Given some non-linear mechanism which ensures preferential movement in the one direction, a climatically induced component of continental drift is therefore possible during glacial periods such as the Quaternary. If so, one might expect that component of drift is intermittent on time-scales between 20 and $100 \mathrm{ka}$, i.e. on time-scales of observed ice-volume variations which, at least over the last $700 \mathrm{ka}$, have been related to the Earth's orbital variations.
\end{abstract}

MANY investigations have confirmed Wegener's (1912) suggestion that on geological time-scales the various continents "drift" from one position to another on the surfacc of the Earth (e.g. Vinc and Matthews, 1963; Westoll, 1965). Maps are now available (Smith and Briden, 1977; Schmidt, 1988) which purport to trace the positions of the continents as far back as $600 \mathrm{Ma}$. Considering only the last $150 \mathrm{Ma}$ for which the positional evidence from palaeoreconstruction is reasonably solid, therc was a break-up of Gondwana in the Southern Hemisphere (effectively, Wegener's "flight from the pole" of South America, South Africa, India and Australia) and a break-up of Laurasia in the Northern Hemisphere as Furasia and North America moved away from one another to form the Atlantic Ocean. The mechanism for continental drift is presumably related to large-scale convection in the Earth's mantle (Peltier, 1989; Olson and others, 1990). One qualitative picture is of a fluid but highly viscous mantle in which up-wellings and down-wellings generate horizontal flows at its surface which carry the floating continental plates. The source of the convection is generally assumed to be differential heating from the core. Divergence of the plates is most clcarly seen in the patterns of magnetic anomalies developed at the spreading mid-ocean ridges (e.g. Veevers and others, 1991).

Since the carly work of Walcott (1973), Cathles (1975) and others, there have been many studies of the verical displacement and subsequent isostatic rebound of those continental plates (or parts of plates) which are subject to extra loading by ice sheets during periods of glaciation. It is largely from these studies that information on the elasticity and rigidity of the lithosphere, and on the vertical profile of viscosity in the mantle, are derived. This note points out that the horizontal components of flow in the mantle induced by the regular (?) cycling of ice-sheet loading and unloading may be of the same order as the observed velocities of continental drift, i.e. some $\mathrm{cm}$ a! Thus, given some non-linear mechanism which ensures preferential movement in the one direction, it is possible, at least for those periods of the Earth's history including the Quaternary when there was significant glaciation, that there could be a climatically induced element to continental drift.

Figure 1 shows the theoretical south to north flow rates of the surface of the upper mantle as a function of latitude at various times during a single $30 \mathrm{ka}$ cycle of ice-sheet loading and unloading of the Antarctic continent. The flow rates were calculated using a very simple " $2 \frac{1}{2}$ dimensional" numerical model with parameters as described in the caption to the figure. It envisages a horizontally uniform upper mantle whose viscosity varies with depth $z$ according to the calculations of Cathles (1975); namely, $1.0 \times 10^{22}$ Poise at all depths down to $1000 \mathrm{~km}$ except for a lowviscosity channel $\left(4.0 \times 10^{20}\right.$ Poise $)$ in the uppermost $100 \mathrm{~km}$. The continental plate corresponding to Antarctica is imagined to float on the mantle from the South Pole to $70^{\circ} \mathrm{S}$, and the rest of the mantle has a free surface at $z=$ 0 . The mantle material is assumed to be inelastic, incompressible and Newtonian. The imposed ice-sheet cycle is a sinusoidal height variation with an amplitude of $1000 \mathrm{~m}$, about half the present thickness of the ice on Antarctica.

The choice of a $30 \mathrm{ka}$ cycle for the illustrative purpose of Figure 1 was not random. During prolonged periods of the Earth's glaciation the volume of icc fluctuates on various time-scales with, at least over the last $700 \mathrm{ka}$, readily observable periods of the order of 20,40 and $100 \mathrm{ka}$. They appear to be related to orbital variations of the Earth about the Sun (Van Woerkum, 19533; Raymo and others, 1990). The last major glacial cycle in the Northern Hemisphere was of the order of $100 \mathrm{ka}$, and much of the work on isostatic rebound (e.g. 'Tushingham and Peltier, 1991) has assumcd a build-up and decay of ice volume over a period of that order. Significant modulation of ice volume at the shorter timc-scales occurred during that and previous cycles, and the illustrative $30 \mathrm{ka}$ cycle was chosen here simply as an order-of-magnitude representation of those shorter time-scales.

Figure 1 reflects the obvious response to extra pressure on Antarctica. Material of the mantle is squeezed from beneath the plate to create a surface sloping downward towards the north and a horizontal component of velocity which at any latitude is a maximum at the surface and which (during the loading part of the cycle) decreases with distance along the great circle away from the Antarctic source. The relaxation-time constant of the model system is about $18 \mathrm{ka}$ (this is from calculations with the model itself), so that during the later part of the cycle, when the load of 


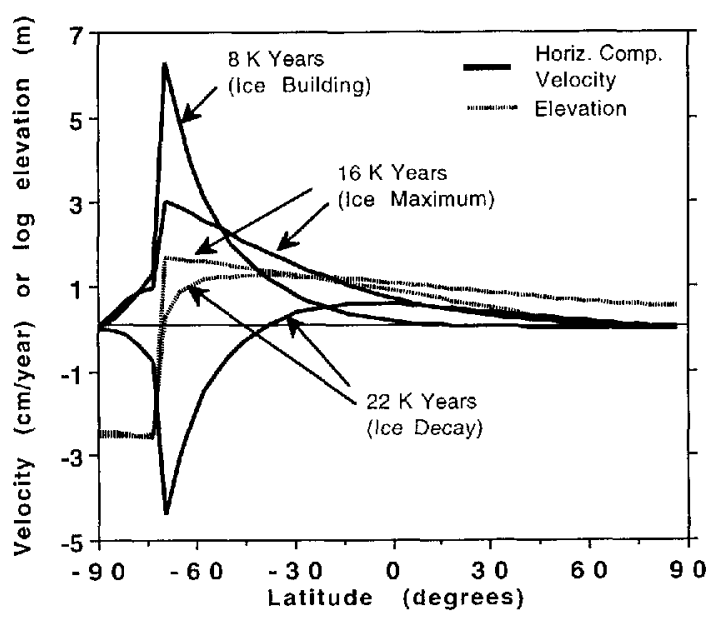

Fig. 1. Computed mantle elevation $H$ (dashed lines) and south to north mantle-surface flow rates $v$ (solid lines) as a funclion of latitude $x$ at zarious times tin a single 30 ka cycle of ice-sheet loading of Anlarctica, according to the following numerical model which solves the one-dimensional steady-state inscous-flow equation $\mathrm{d} p / \mathrm{d} x=-\mu(z) \mathrm{d}^{2} v / \mathrm{d} z^{2}$. Grid spacing: 225 interzals of lalitude from South to Vorth Pole, 20 depth levels from $z=0$ to $z=z_{\mathrm{d}}=1000 \mathrm{~km}$, one intercal in the east-ivest $(y)$ direction of unit width at the Equator but varying as $\cos x$. Viscosity profile $\mu(z)$ as given in the text. Excess pressure $p$ due to imposed ice load on Antartica (from $x=-90^{\circ}$ to $\left.-70^{\circ}\right)=p_{0}(x, t)=\rho g h(t)$ where $h(t)=h_{0}-h_{0} \cos (2 \pi t / 30000)$ with $h_{0}=1000 \mathrm{~m}$, $g=$ accleration due to gravity and $\rho=$ density of ice $=$ $1000 \mathrm{~kg} \mathrm{~m}^{-3}$. Viscous transfer in the horizonlal direction is translated inlo mantle elevation $H(x)$ and hence excess pressure assuming density of manlle $=4000 \mathrm{~kg} \mathrm{~m}^{3}$. Flow-boundary conditions of $v\left(x, z_{1}\right)=0, v(x, 0)=0$ at all $x$ from $-90^{\circ}$ to $70^{\circ}, \mathrm{d} v / \mathrm{d} z=0$ elsewhere. The time step was 1 year.

ice is reducing, there is still a northward velocity at latitudes close to the North Pole.

The system as described is linear, so that flows in the mantle induced by the increased pressure beneath Antarctica during the loading part of the glacial cycle are reversed during the unloading part of the cycle. If the loading-unloading cycle is regularly repeated, the system settles down to a form of steady state where the azerage velocities over a complete cycle are zcro. To propose that the icc-loading process is significant in the context of longtcrm continental drift requires one to propose also some form of non-linear hystcresis which favours flow (or, at least, the actual movement of floating continental plates) in one direction. It is not difficult to suggest a number of possible mechanisms. It is vcry difficult to justify them. The simplest suggestion (more or less in line with the modern investigations of plate tectonics and the formation of midoccan ridges) is that magma from the mantle wells up into the opening between two diverging continental plates, where it cools and solidifies to a material which is highly resistant to compression but poorly resistant to expansion (Jaeger and Cook, 1976). A floating continent which is carried in one direction by horizontal flow in the mantle would therefore be restrained from moving backward when the flow in the mantle reverses. Perhaps the main attraction of the suggestion is that it might in principle be checkable, since it implies a component of continental drift which is intermittent on the time-scale of sevcral tcns of thousands of years. Such checking would require, say, development of some technique for examining the Quaternary stratigraphic chronology of the mid-ocean ridges at a level of detail much greater than that allowed by present magnetic-reversal stratigraphy.

Setting aside questions about what might be the most appropriate profiles of density and viscosity to use in a model, the present calculations involve a number of gross simplifications. For instance, the depth of the model is confined to that of the upper mantle about $1000 \mathrm{~km}$ ) simply to give some "floor" at which to sct a boundary condition of zero velocity. (There is some evidence (Bot, 1971) to suggest that convection does not penctrate the boundary between the lower and upper mantle, although this does not necessarily excuse the neglect in the present context of viscous flow in the lower mantle. In any event, a larger model depth would yield greater velocities at the surfacc.) For instance, again, the "free" mantle surface is equivalent to assuming that drag of the continental plates by mantle flow is a viable mechanism for drift (Forsyth and Lycda, 1975).

Despite the various simplifications, when the model is used to compute the prescnt-day horizontal velocities associated with the most recent post-glacial rebound of North America, the results (see Fig. 2) are remarkably similar to those of James and Morgan (1990), whose whole-Earth model includes specific consideration of such things as visco-elasticity of the mantle and rigidity of the lithospherc. The smaller velociry of the James and Morgan model near the ice-sheet edge is probably due to their (more realistic?) assumption of a parabolic height profile across the ice sheet, and to the smoothing effect of the lithosphere included in their model.

Figure 3 shows computed average mantle-surface velocities where the averages at each latitude are taken over the loading half of a sinusoidal loading-and-unloading cycle. An increase of cycle time from 30 to $100 \mathrm{ka}$ reduces the average velocities by a factor of 2 , as might be expected anyway from consideration of the time constant of the system. If the low-viscosity channel is removed, so that all levels of the mantle have a viscosity of $1.0 \times 10^{22}$ Poise, the velocities at angular distances greater than $60^{\circ}$ from the glacial centre (i.e. from the South Pole) are reduced to levels below $0.1 \mathrm{~cm} \mathrm{a}^{-1}$. The importance of the low-riscosity channel in determining the distribution of horizontal velocity is also apparent in the comparisons of Figure 2.

Figure 4 shows the gcographical distribution of mantlcsurface flow rates computed as the vector sum of the greatcircle flow rates associated with icc loading of Antarctica and of a continent of equivalent size centered on $70^{\circ} \mathrm{N}$. 'The picture is broadly (very broadly) consistent with the present movement of the continents, i.e. roughly southnorth in the Southern Hemisphere and roughly east-west in the Northern Hemispherc. "Roughly" should be emphasized here. It can be gauged by reference to the known patterns of sea-floor spreading as, for instance, in Press and Sicver (1982). While the result in no way suggests that the mechanism suggested here is the primary cause of continental drift (either now or in glacial periods of the past;, it is at least possible that the process amplifics certain directional components of an already established drift.

In summary, the existence of extended glacial periods 


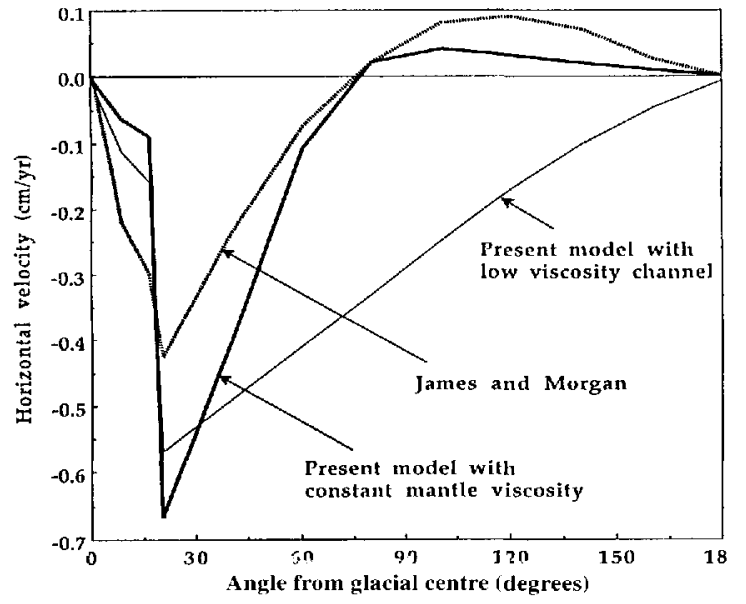

Fig. 2. Present-day horizontal component of mantle-surface velocities (positive away from the glacial centre) as a function of angular distance from the centre of the last North American ice sheet, which is assumed to have increased linearly in height from zero to a maximum $(1 \mathrm{~km})$ over a period of $90 \mathrm{ka}$, and decreased linearly back to zero by $100 \mathrm{ka}$ (i.e. by $6000 \mathrm{a} \mathrm{BP}$ ). The dashed curve is from the detailed model of James and Morgan (1990), the thick solid curve is from the present model with a constant manlle viscosity of $1.0 \times 10^{22}$ Poise (as for James and Morgan), and the thin solid curve shows the effect of a low-viscosity channet as discussed in the reference to Figure 1.

on Earth secms to require a continent cither to be very near a Pole or to have a significant fraction of its surface at high elevation (Budd and Smith, 1979). The Earth has been largely ice-free for much of its history but, during glacial periods such as the Quaternary, the cyclical loading and unloading of ice may contribute significantly to continental drift. The main proviso is that there exists some non-lincar mechanism associated with platc-mantlc interaction which acts as a "ratchel" to ensure preferential movement of the continental plates in the one direction.

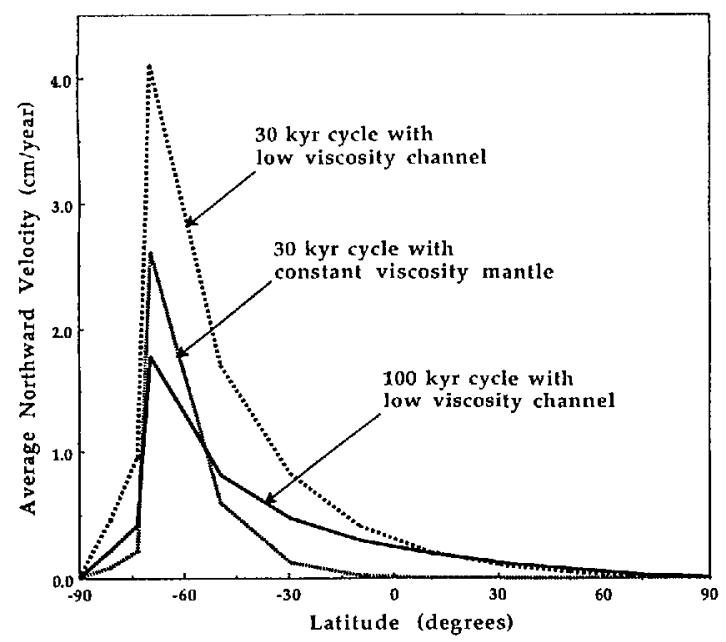

Fig. 3. Time-azeraged northward velocities for the "increasing load" half of a South Polar sinusoidal icesheet cycle. The curve's refer lo a $30 \mathrm{ka}$ imposed cycle with a low-riscosity channel in the upper mantle (i.e. comparable with the conditions in Figure 1), a $30 \mathrm{ka}$ cycle with a constant mantle viscosity of $1.0 \times 10^{22}$ Poise and a $100 \mathrm{ka}$ cycle with a low-riscosity channel as in Figure 1.

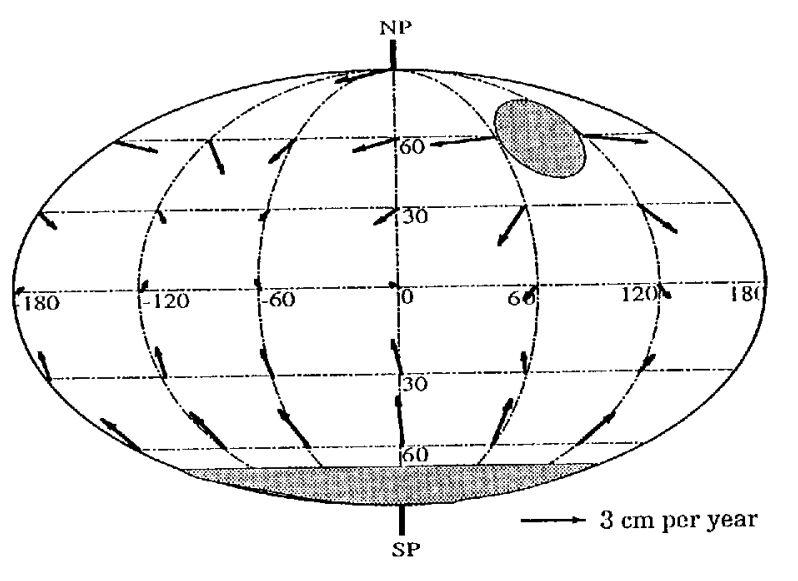

Fig. 4. Geographical distribution of mantle-surface velocities for two ice sheets positioned as shown by shaded areas, each at $16 \mathrm{ka}$ into an ice-loading cycle as in Figure 1. The calibration arrow outside the globe of length is equivalent to a velocity of $3.0 \mathrm{~cm} \mathrm{a}^{-7}$.

\section{REFERENCES}

Bott, M. H. P. 1971. The interior of the Earth. London, Edward Arnold. Budd, W.F. and I. N. Smith. 1979. The growth and retreat of ice shects in response to orbital radiation changes. International Association of H)drological Sciences Publication 131 Symposium at Canberra 1979 Sea Level, Ice and Climate Changei. 369-409.

Cathles, L. M. 1975. The riscosity of the Eath's mantie. Princeton, Princeton University Press.

Forsyth, D. and S. Lyeda. 1975. On the relative importance of the driving forces of plats motion. Genphys. 7. R. Astr. Soc, 43, 163-200.

Jaeger, J.C. and N.G.W. Cook. 1976. Fundamentals of rock mechanics. London, Chapman and Hall, Ltd. and Science Paperbacks.

James, T.S. and W.J. Morgan. 1990. Horizontal motions due to postglacial rcbound. Geophys. Res. Lett., 17, 957-960.

Olson, P., P.G. Silver and R. W. Carlson. 1990. The large-scale structure of convection in the Earth's mantle, Vature, 344, 209.215.

Pelticr, W. R. 1989. In Pclticr, W. R., ed. Mantle convection: plate tectonics and global dynamics. New York, Gordon and Breach, 1-22.

Press, F, and R. Siever, 1982. Eath. San Francisco, Freeman and Co.

Raymo, M. E., W.F. Ruddiman. N.J. Shackleton and D. W. Oppo. 1990. Fvolution of Atlantic-Pacitic $\delta^{13} \mathrm{C}$ gradients over the last 2.5 m.y. Earth Planet. Sci. Lett., 97, 353-368.

Schmidt, V. A. 1988. Continental drift. (Hypercard Program from Gcoimages. 1307 Ridgemont Dr., Austin, Trxas 78723.

Smith, A. G. and J. C. Briden. 1977. Mesozuic and Cenozoic paleo-continental maps. Cambridge, Cambridge Lniversity Press.

Tushingham, A. M. and W. R. Pclticr. 1991. A now global model of late Pleistocene deglaciation based upon geophysical predictions of postglacial relative sea level change. $j$. Geophys. Res., 96(B3), 4497-4523.

Van Wocrkum, A.J.J. 1953. The astronomical theory of climate change. In Shapley, H., ed. Climale change. Cambridge, MA, Harvard University Press.

Veevers, J.J., C. McA. Powell and S. R. Roots. 1991. Review of seafloor spreading around Australia. 1. Synthesis of the patterns of spreading. Aust. F. Earth Sci, 38, 373-389.

Vine, F.J. and D. H. Matthews. 1963. Magnetic anomalies over ocean ridges. Vature, 199, $947-949$.

Walcott, R. I. 1973. Structure of the Farth from glacio-isostatic rebound. Ann. Re?. Eanth Planet. Sci., 1, 15-37.

Wegener, A. 1912. Die Entstehung der Kontinente. Peterm. Miti., 1912, $185-195,253-256,305-309$.

Westoll, T. S. 1965. Geological evidence bearing upon continental drift In "A symposium on continental drift". Phil. Trans. R. Soc. A., 258, $12-26$.

The accuracy of references in the text and in this list is the responsibility of the aulhor, 10 whom queries should be addressed. 